\title{
Modificação da Rugosidade de Fibras de Carbono por Método Químico para Aplicação em Compósitos Poliméricos
}

\author{
Liliana Burakowski \\ Departamento de Física, ITA \\ Mirabel C. Rezende \\ Divisão de Materiais, Instituto de Aeronáutica e Espaço, CTA
}

Resumo: O presente trabalho aborda o tratamento superficial de fibras de carbono por ácidos clorídrico e nítrico, visando o aumento controlado da rugosidade superficial da fibra e assim melhorar a ligação fibra/matriz no processamento de compósitos poliméricos reforçados com fibras longas. Foram utilizadas fibras de carbono com size, da empresa Toray. Essas foram tratadas com os ácidos clorídrico e nítrico, a $103^{\circ} \mathrm{C}$, em concentrações de $35,5 \%$ e $97 \%$, em massa, respectivamente, em tempos de exposição de 5, 10, 20, 30, 40 e 60 minutos. As fibras modificadas quimicamente foram caracterizadas por microscopia eletrônica de varredura e por ensaios mecânicos de tração e os dados foram tratados pelo método estatístico de Weibull. Os resultados mostram que os tratamentos empregados modificam a superfície da fibra e que períodos de tratamento superiores a 20 minutos as danificam, degradando de maneira significativa as suas propriedades mecânicas.

Palavras-chave: Fibras de carbono, tratamento superficial, interface.

\section{Carbon Fibers Roughness Modification by Chemical Methods for Application in Polymeric Composites}

Abstract: The present work concerns the surface treatment of carbon fibers using hydrochloric and nitric acids treatment, so as to control the increase in surface roughness in order to improve the fiber/matrix interface of long fiber reinforced polymer composites. Sized carbon fibers from Toray were used. The samples were treated using hot hydrochloric and nitric acids $\left(103^{\circ} \mathrm{C}\right)$ in concentrations of $35.5 \%$ and $97 \%$, by weight respectively, at exposition times of 5, 10, 20, 30, 40 and 60 minutes. The chemically treated fibers were characterized by scanning electronic microscopy and tensile strength tests, assisted by Weibull statistics. It was found that the treatments employed modify the surface of the fibers and exposition periods longer than 20 minutes cause considerable degradation of their mechanical properties.

Keywords: Carbon fibers, surface treatment, interface.

\section{Introdução}

As fibras de carbono são, freqüentemente, o tipo de reforço mais utilizado no processamento de compósitos estruturais de matriz polimérica ${ }^{[1]}$. Essas destacam-se entre as outras fibras, por sua alta resistência mecânica, alto módulo de elasticidade e menor massa específica, além de propriedades como inércia química, resistência térmica e condutividade elétrica. Entretanto, sabe-se que a fibra de carbono possui baixa afinidade com determinadas matrizes poliméricas (fraca interface) dificultando, assim, a adesão fibra/matriz, fator determinante para o sucesso da aplicação desses materiais ${ }^{[1]}$.

A adesão fibra/matriz pode ser atribuída a cinco mecanismos principais que podem ocorrer na interface: adsorção e molhamento; interdifusão; atração eletrostática; ligação química e adesão mecânica ${ }^{[1,3]}$.

Autor para correspondência: Mirabel C. Rezende, CTA/IAE - Divisão de Materiais, Pça. Mal. Eduardo Gomes 50, Vila das Acácias, CEP: 12228-904, São José dos Campos,SP.E-mail:mirabel@iae.cta.br 
Muito freqüentemente, as interações físicas e químicas entre a fibra e a matriz conduzem a um gradiente de estruturas. Essa região interfacial, responsável pelo processo de adesão, é conhecida como interfase ${ }^{[4]}$. A Figura 1 apresenta um diagrama esquemático do conceito de interface e interfase em material compósito ${ }^{[4]}$. A adesão em um compósito polimérico pode se dar por encaixe mecânico de cadeias da matriz polimérica em rugosidades existentes na superfície da fibra, atração eletrostática, forças de van der Waals ou formação de ligações químicas mais fortes ${ }^{[5]}$.

Uma interface fibra/matriz forte aumenta a integridade dos compósitos e transfere a carga eficientemente às fibras, através da matriz, resultando em compósitos mais resistentes. Com o propósito de aumentar a atividade superficial e, conseqüentemente, melhorar a transferência de tensões em compósitos, o reforço pode ser submetido a diferentes processos de tratamento superficial ${ }^{[2]}$.

O tratamento superficial da fibra de carbono pode ser realizado por meio de métodos químicos, pela ação de substâncias oxidantes, oxidação eletroquímica ou anódica, ou métodos que envolvem tratamentos térmicos. Os tratamentos oxidativos podem ser melhor divididos em oxidação por gases a seco, incluindo etching (corrosão) por plasma de gases oxidantes e oxidação úmida, realizada química ou eletroliticamente. Já os tratamentos não-oxidativos podem incluir a deposição de formas ativas de carbono, como o tratamento altamente eficaz de whiskerização, que é porém caro; a polimerização por plasma ou a aplicação de uma fina camada de polímero na superfície da fibra de carbono, denominada de size, com o objetivo de proteger o reforço de danos externos e me-

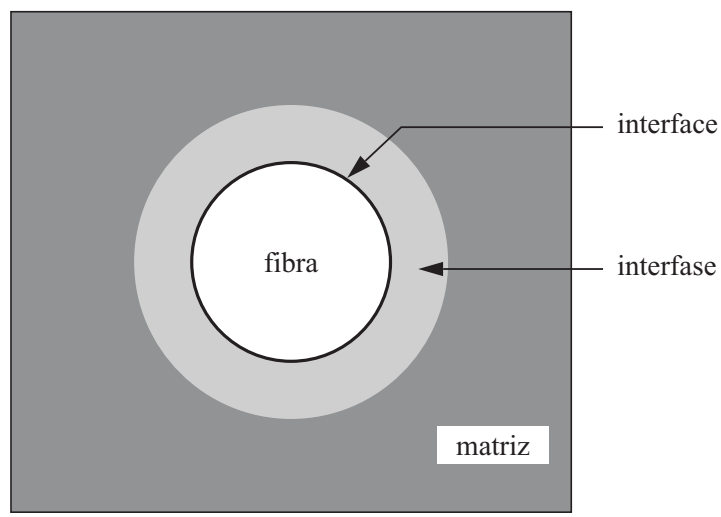

Figura 1. Diagrama esquemático apresentando conceitos de interface e interfase em materiais compósitos ${ }^{[4]}$. lhorar a sua adesão à determinadas matrizes poliméricas ${ }^{[4]}$. O método mais freqüentemente utilizado em escala industrial, com resultados satisfatórios, é a oxidação anódica ou eletroquímica. $\mathrm{O}$ que basicamente ocorre nesse processo é a formação de grupos superficiais ativos, que se ligam quimicamente à matriz polimérica.

A utilização do tratamento oxidativo da superfície da fibra de carbono por meios líquido ou gasoso, pode gerar grupos funcionais contendo oxigênio e ao mesmo tempo proporcionar o aumento da área superficial da fibra ${ }^{[5]}$. Vários tipos de oxidação à base de agentes na fase líquida como, por exemplo, ácido nítrico, permanganato de potássio, dicromato de potássio, hipoclorito de sódio, peróxido de hidrogênio e persulfato de potássio têm sido utilizados com diferentes graus de sucesso. Vários fatores, tais como: a concentração do ácido, o tempo de exposição, a temperatura e o modo de tratamento influenciam efetivamente nesses processos oxidativos, podendo gerar funcionalidade e o aparecimento de óxidos na superfície tratada e, ainda, um aumento da área superficial, pela formação de pequenos poros/depressões ou o aparecimento de sulcos longitudinais, facilitando a ancoragem mecânica e a interpenetração entre a fibra e a matriz ${ }^{[4]}$.

Com a utilização dos ácidos clorídrico e nítrico no tratamento superficial de fibras de carbono, espera-se obter grupos funcionais, tais como: hidroxila e carboxila, que possam se combinar com a matriz polimérica, permitindo uma maior adesão entre o sistema fibra/matriz. A Figura 2 apresenta um modelo esquemático com alguns dos grupos funcionais que podem ser encontrados na superfície das fibras de carbono após o tratamento oxidativo ${ }^{[6]}$.

Com o objetivo de aumentar de maneira controlada a rugosidade da superfície de cabos de fibras de carbono, a fim de melhorar a interface fibra/matriz no processamento de compósitos com matrizes

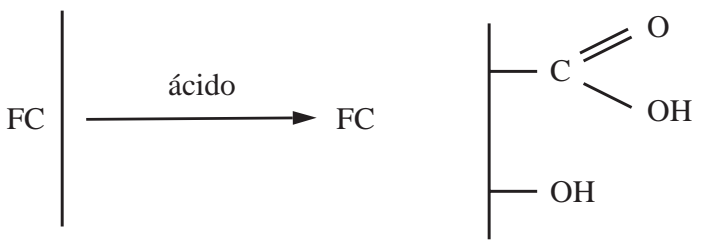

Figura 2. Modelo esquemático com alguns dos grupos funcionais que podem ser gerados na superfície de fibras de carbono (FC) tratadas por ácidos $^{[6]}$. 
poliméricas, o presente trabalho estudou a indução da mudança superficial deste tipo de reforço pelo uso de dois oxidantes em fase líquida, os ácidos clorídrico e nítrico, em diferentes tempos de exposição, avaliando as fibras tratadas por meio de ensaios de tração e observações por microscopia eletrônica de varredura.

\section{Experimental}

Foram utilizadas, neste trabalho, fibras de carbono com size de resina epóxi adquiridas da empresa Toray, em forma de cabos, constituídos por 3000 filamentos de fibras de carbono, com massa específica de $1,75 \mathrm{~g} / \mathrm{cm}^{3}$. Foram utilizados ácidos clorídrico e nítrico de procedência Merck, grau P.A., nas concentrações de $35,5 \%$ e $97 \%$, em massa, respectivamente. As fibras foram tratadas nas soluções dos ácidos concentrados, em tempos de 5, 10, 20, 30, 40 e 60 minutos, à temperatura de $103^{\circ} \mathrm{C}$, em chapa de aquecimento, sem agitação.

Após o tratamento químico, as fibras foram lavadas em água deionizada recém fervida e posteriormente secadas em estufa a $60^{\circ} \mathrm{C}$ até peso constante (cerca de 2 horas). Foram obtidos 12 lotes de amostras de fibras de carbono tratadas pelos ácidos clorídrico e nítrico.

Após os tratamentos ácidos, a resistência à tração dos lotes das fibras de carbono foi avaliada segundo a norma ASTM D 3379-75 ${ }^{[7]}$, com a preparação de 30 corpos-de-prova para cada lote e os resultados obtidos foram tratados utilizando-se o método estatístico de Weibull ${ }^{[8,9]}$. Nas determinações de resistência à tração foi utilizada uma máquina universal de ensaios Instron, da Divisão de Materiais do AMR/CTA, com velocidade de ensaio de $2,5 \mathrm{~mm} / \mathrm{min}$.
As análises das superfícies das fibras foram realizadas utilizando-se um microscópio eletrônico de varredura da Zeiss modelo 950, sem nenhuma preparação especial das amostras e as micrografias foram obtidas na magnificação de 30.000 vezes.

\section{Resultados e Discussão}

A seguir são apresentados os resultados obtidos nos ensaios de resistência à tração usando o método estatístico de Weibull e por microscopia eletrônica de varredura dos 12 lotes de fibras de carbono tratados por 5, 10, 20, 30, 40 e 60 minutos em ácidos clorídrico e nítrico. Na Tabela 1 são apresentados os valores dos ensaios de resistência à tração e dos parâmetros de Weibull, obtidos nos tratamentos feitos com o ácido clorídrico e de uma amostra que não foi submetida a nenhum tratamento, sendo considerada a amostra de referência.

A curva apresentada na Figura 3 foi ajustada por regressão polinomial-grau 2 e mostra os resultados de resistência à tração das fibras de carbono, tratadas e não tratadas. A análise desta curva mostra um decréscimo na resistência das fibras para os tratamentos entre 5 e $20 \mathrm{~min}$. Observa-se, também, que tempos de tratamento superiores a 20 minutos fazem com que o valor médio da resistência à tração mostre um aparente acréscimo em seus valores.

O ligeiro aumento nos valores de resistência à tração observado na Figura 3 para os tempos de tratamento de 40 e $60 \mathrm{~min}$ é explicado pelo fato das fibras de carbono terem sido tratadas quimicamente na forma de cabos, sendo cada cabo constituído de aproximadamente 3000 filamentos de fibras, favorecendo um ataque ácido não homogêneo dos filamentos, principalmente, nos mais internos ao cabo. Em função disso, foi verificado que

Tabela 1. Valores mínimo, médio e máximo de resistência à tração $(\sigma)$, desvio padrão e módulo de Weibull $(m)$ de amostras de fibra de carbono, com size, tratadas com ácido clorídrico.

\begin{tabular}{|c|c|c|c|c|c|c|c|}
\hline $\begin{array}{c}\text { Tratamento } \\
\text { Ácido } \\
\text { Clorídrico }\end{array}$ & $\begin{array}{c}\text { Referência } \\
\sigma(\mathrm{MPa})\end{array}$ & $\begin{array}{c}5 \mathrm{~min} \\
\sigma(\mathrm{MPa})\end{array}$ & $\begin{array}{c}10 \mathrm{~min} \\
\sigma(\mathrm{MPa})\end{array}$ & $\begin{array}{c}20 \mathrm{~min} \\
\sigma(\mathrm{MPa})\end{array}$ & $\begin{array}{c}30 \mathrm{~min} \\
\sigma(\mathrm{MPa})\end{array}$ & $\begin{array}{c}40 \mathrm{~min} \\
\sigma(\mathrm{MPa})\end{array}$ & $\begin{array}{c}60 \mathrm{~min} \\
\sigma(\mathrm{MPa})\end{array}$ \\
\hline Mínimo & 1153 & 1064 & 1020 & 532 & 133 & 177 & 488 \\
\hline Médio & 2143 & 2022 & 2040 & 1824 & 1179 & 1459 & 1727 \\
\hline Máximo & 3104 & 2749 & 2705 & 2749 & 2439 & 2217 & 2306 \\
\hline Desvio padrão & 471 & 443 & 489 & 644 & 670 & 539 & 449 \\
\hline $\mathrm{m}$ & 3,46 & 3,17 & 2,97 & 1,87 & - & - & - \\
\hline
\end{tabular}




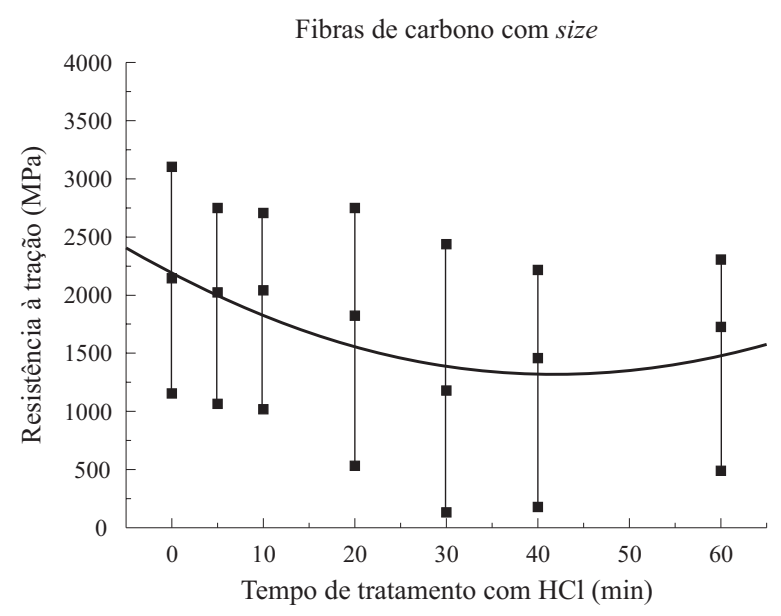

Figura 3. Resistência à tração da fibra de carbono em função do tempo de tratamento no ácido clorídrico.

os tratamentos ácidos provocaram um ataque preferencial nos filamentos de fibras de carbono mais periféricos ao cabo, sendo que quanto maior foi o tempo de exposição do reforço ao ácido, mais acentuado foi esse ataque. Ao serem preparados os corpos-de-prova para os ensaios de resistência à tração, foi observado que as fibras expostas por mais de 30 minutos na solução ácida apresentavam pouca resistência, sendo os monofilamentos utilizados na preparação dos corpos-de-prova de difícil manuseio. Devido a este ataque químico diferenciado aos filamentos de fibras, durante a preparação dos corpos-de-prova escolheram-se, aleatoriamente, os filamentos mais internos ao cabo e menos atacados pelo ácido, que se mostravam mais resistentes e de mais fácil manipulação, induzindo, assim, a valores de resistência à tração não representativos da amostra tratada.

Assim, considerando-se o decréscimo ocorrido na resistência da amostra tratada por $30 \min (\sim 45 \%)$, somado ao perfil não representativo do comportamento mecânico das fibras de carbono tratadas qui- micamente por 40 e $60 \mathrm{~min}$, foi concluído que os tempos iguais ou superiores a 30 min não foram adequados no tratamento das amostras do reforço em estudo.

A análise da Tabela 1 mostra, também, que os valores de desvio padrão para as amostras de referência e tratadas por 5 e $10 \mathrm{~min}$ apresentam valores da mesma ordem de grandeza e os valores médios de resistência para as amostras tratadas por 5 e 10 min diminuíram em 5,6 e 4,8 \% em relação à amostra de referência, respectivamente. Para os tempos de 20, 30 e 40 min o desvio padrão aumenta, sugerindo uma maior heterogeneidade da amostra ensaiada.

A Tabela 2 apresenta os resultados dos ensaios de resistência à tração e dos parâmetros estatísticos obtidos pelo método de Weibull $(\mathrm{m})$ referentes aos tratamentos feitos com o ácido nítrico.

A Figura 4 relaciona os dados das fibras de carbono tratadas com o ácido nítrico. Pode-se observar no gráfico da Figura 4 que os valores médios de resistência à tração nos tempos de tratamento de 5, 10 e 20 min têm uma queda progressiva em seus valores. Porém, nos tempos de 30 e 40 min de tratamento, os valores médios de resistência à tração aumentam, apresentando o mesmo comportamento discutido para as amostras tratadas com o ácido clorídrico. No caso das amostras de fibras de carbono tratadas por $60 \mathrm{~min}$ foi observado que os valores de resistência média e de desvio padrão diminuíram, em relação aos tratamentos por $30 \mathrm{e}$ $40 \mathrm{~min}$. Este fato ocorreu devido ao maior tempo de tratamento e ao maior poder oxidante do ácido nítrico favorecerem um ataque mais homogêneo do cabo de fibras. Para os tempos de 5 e 10 min os valores médios da resistência à tração diminuíram em 7,3 e $10 \%$ em relação à amostra de referência, respectivamente.

Tabela 2. Valores mínimo, médio e máximo de resistência à tração $(\sigma)$, desvio padrão e de módulo de Weibull $(m)$ de amostras de fibra de carbono, com size, e tratadas com ácido nítrico.

\begin{tabular}{lccccccc}
\hline \multicolumn{1}{c}{$\begin{array}{c}\text { Tratamento } \\
\text { Ácido Nítrico }\end{array}$} & $\begin{array}{c}\text { Referência } \\
\boldsymbol{\sigma}(\mathbf{M P a})\end{array}$ & $\begin{array}{c}\mathbf{5} \mathbf{~ m i n} \\
\boldsymbol{\sigma}(\mathbf{M P a})\end{array}$ & $\begin{array}{c}\mathbf{1 0} \mathbf{~ m i n} \\
\boldsymbol{\sigma}(\mathbf{M P a})\end{array}$ & $\begin{array}{c}\mathbf{2 0} \mathbf{~ m i n} \\
\boldsymbol{\sigma}(\mathbf{M P a})\end{array}$ & $\begin{array}{c}\mathbf{3 0} \mathbf{m i n} \\
\boldsymbol{\sigma}(\mathbf{M P a})\end{array}$ & $\begin{array}{c}\mathbf{4 0} \mathbf{~ m i n} \\
\boldsymbol{\sigma}(\mathbf{M P a})\end{array}$ & $\begin{array}{c}\mathbf{6 0} \mathbf{~ m i n} \\
\boldsymbol{\sigma}(\mathbf{M P a})\end{array}$ \\
\hline Mínimo & 1153 & 1064 & 843 & 177 & 355 & 1020 & 798 \\
Médio & 2143 & 1986 & 1924 & 1531 & 1765 & 2026 & 1583 \\
Máximo & 3104 & 2971 & 2926 & 2217 & 2838 & 3459 & 2439 \\
Desvio padrão & 471 & 522 & 658 & 605 & 635 & 663 & 469 \\
$\mathrm{~m}$ & 3,46 & 2,77 & 2,10 & 1,28 & - & - & - \\
\hline
\end{tabular}




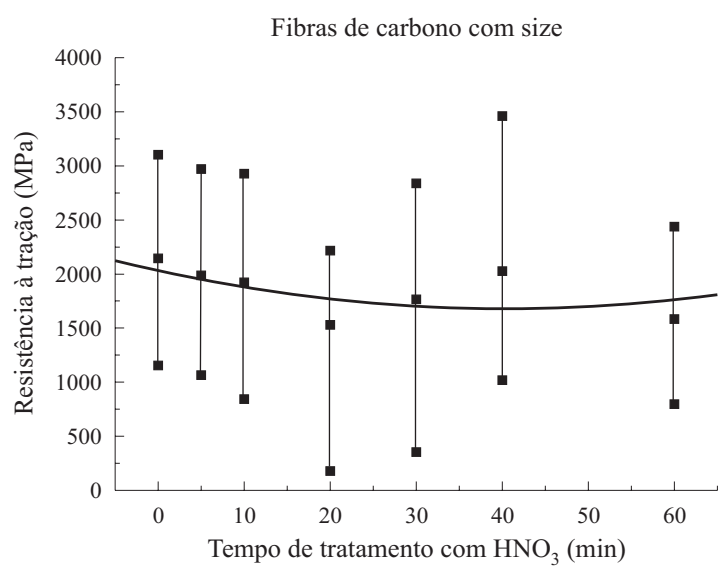

Figura 4. Resistência à tração da fibra de carbono em função do tempo de exposição ao ácido nítrico

\section{Estatística de Weibull}

Como os valores de resistência à tração dos lotes de fibras tratados nos tempos de 30, 40 e 60 minutos não são representativos de cada condição de tratamento, foram apresentados nas Tabelas 1 e 2 os resultados da análise da estatística de Weibull das fibras de carbono submetidas aos tratamentos ácidos por 5, 10 e 20 minutos.

Pode-se observar na Tabela 1 que o módulo de Weibull $(m)$ da amostra de fibras utilizada como referência é maior do que os das fibras tratadas quimicamente. $\mathrm{O}$ valor de $m$, que para amostra não tratada é igual a 3,46 , apresenta uma queda em seus valores para 3,17;2,97 e 1,87, para os tratamentos de 5, 10 e 20 minutos, respectivamente. Sabendo-se que, os valores de $m$ estão relacionados com a presença de defeitos no material analisado e que a introdução de um maior número de defeitos provoca o decréscimo do módulo de Weibull ${ }^{[8,9]}$, pode-se concluir que as fibras de carbono sem tratamento químico apresentam um menor número de defeitos em sua superfície e que o aumento do tempo de exposição do reforço ao ataque ácido, favoreceu o aparecimento destes na superfície do filamento de carbono.

A Tabela 2 apresenta os valores de módulo de Weibull de 2,77; 2,10 e 1,28 para as fibras de carbono tratadas com ácido nítrico por 5, 10 e 20 minutos, respectivamente. Pode ser observado que os valores de $m$ das fibras tratadas com o ácido nítrico também diminuíram em relação à amostra de referência, como observado para as fibras tratadas com o ácido clorídrico. Porém, ao comparar este parâmetro calculado para as fibras tratadas com os diferentes ácidos observa-se que, as amostras expostas ao ácido nítrico apresentam uma queda mais acentuada em seus valores de $m$. Isto evi- dencia que o número de defeitos introduzidos na superfície da fibra pelo tratamento superficial com o ácido nítrico é maior em relação ao do tratamento com o ácido clorídrico. Esta tendência de $m$ calculado concorda com os maiores valores de desvio padrão para os tempos de 5 e 10 min e a maior queda da resistência em tração das amostras tratadas com o ácido nítrico.

\section{Análise por microscopia eletrônica de varredura}

A fotomicrografia apresentada na Figura 5 foi obtida na magnificação de $30.000 \mathrm{X}$ e mostra a fibra de carbono com size, utilizada como referência. Podese observar que esta apresenta a rugosidade característica de fibras de carbono obtidas pelo processo de carbonização de filamentos de poliacriloniltrila, por fiação a úmido ${ }^{[10]}$. A textura observada se caracteriza por uma região levemente estriada, com sulcos pouco profundos.

A seguir são apresentadas as fotomicrografias representativas das fibras de carbono tratadas com os ácidos clorídrico e nítrico, obtidas por microscopia eletrônica de varredura (Figuras 6 (a), (b) e (c) e 7 (a), (b) e (c)).

Comparando-se a fotomicrografia da Figura 5 (fibra utilizada como referência) com as fibras tratadas com $\mathrm{HCl}$ por 5 e 10 minutos, Figuras 6 (a) e (b), respectivamente, pode-se observar, na magnificação utilizada para análise, que o tratamento por 5 minutos não provocou alteração significativa da rugosidade superficial do reforço, enquanto que o tratamento por 10 minutos acentuou a profundidade dos sulcos no sentido longitudinal das fibras. A Figura 6 (c) mostra um filamento de fibra de carbono tratado por $20 \mathrm{~min}$ com o ácido clorídrico, podendo-se observar que o acabamento superficial da amostra apresenta-se bem mais

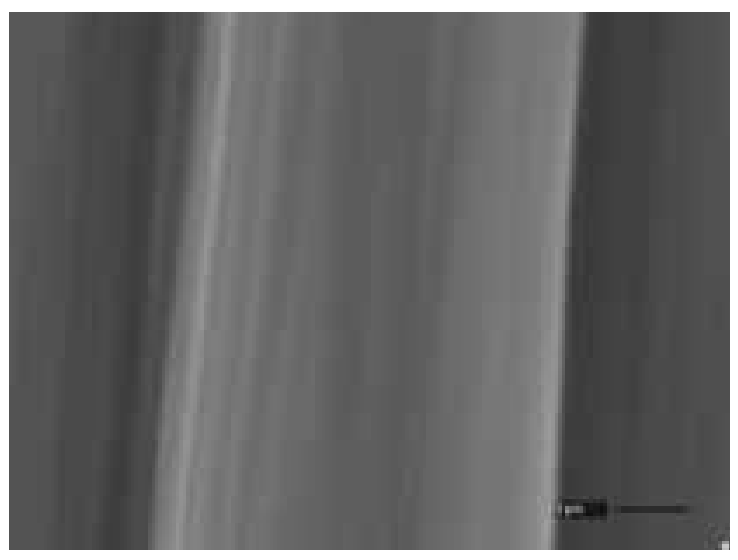

Figura 5. Fibra de carbono com size, amostra de referência. 

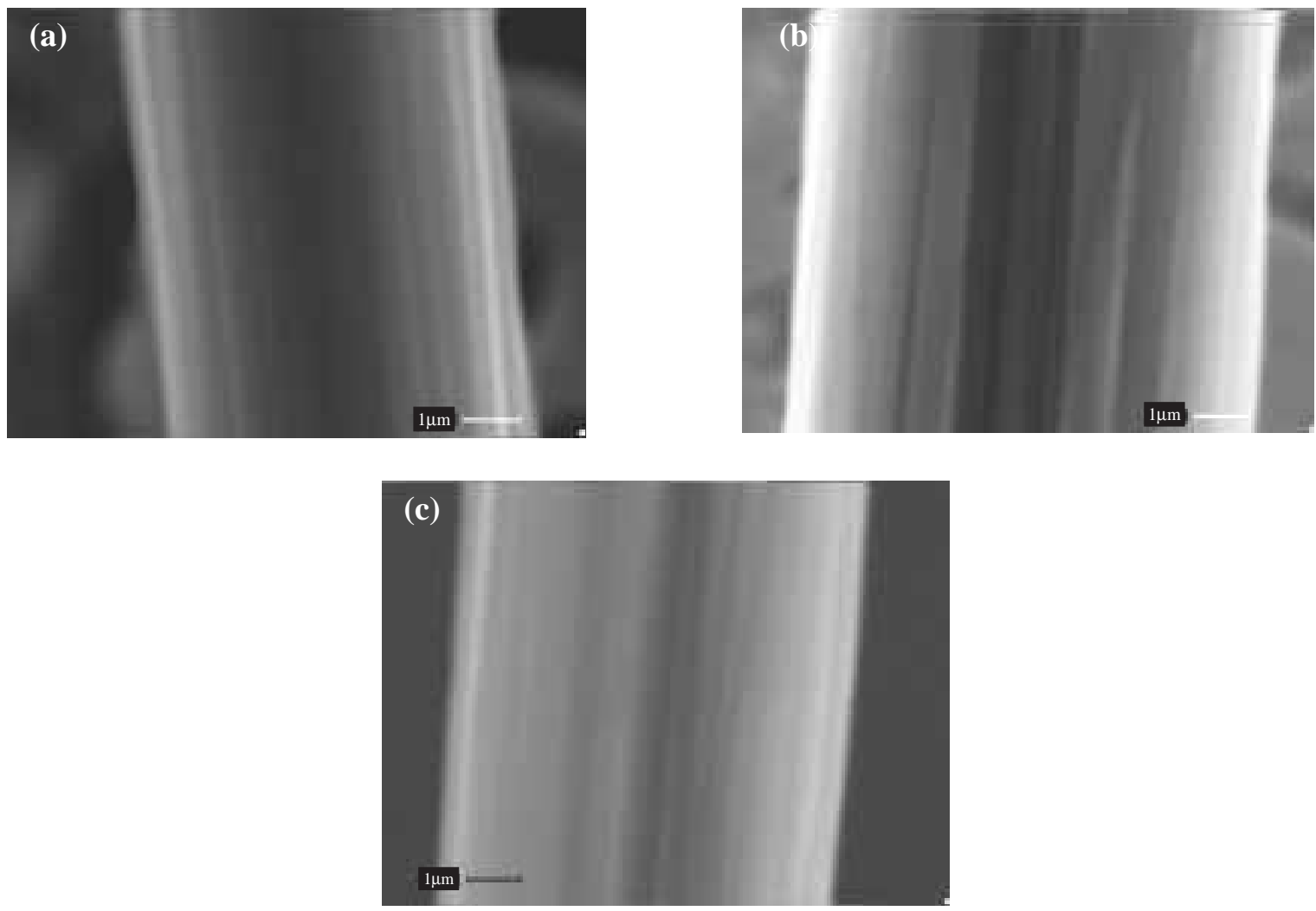

Figura 6. (a) Fibra de carbono tratada com $\mathrm{HCl}$ por 5 min.; (b) Fibra de carbono tratada com $\mathrm{HCl}$ por 10 min.; (c) Fibra de carbono tratada com $\mathrm{HCl}$ por 20 min.
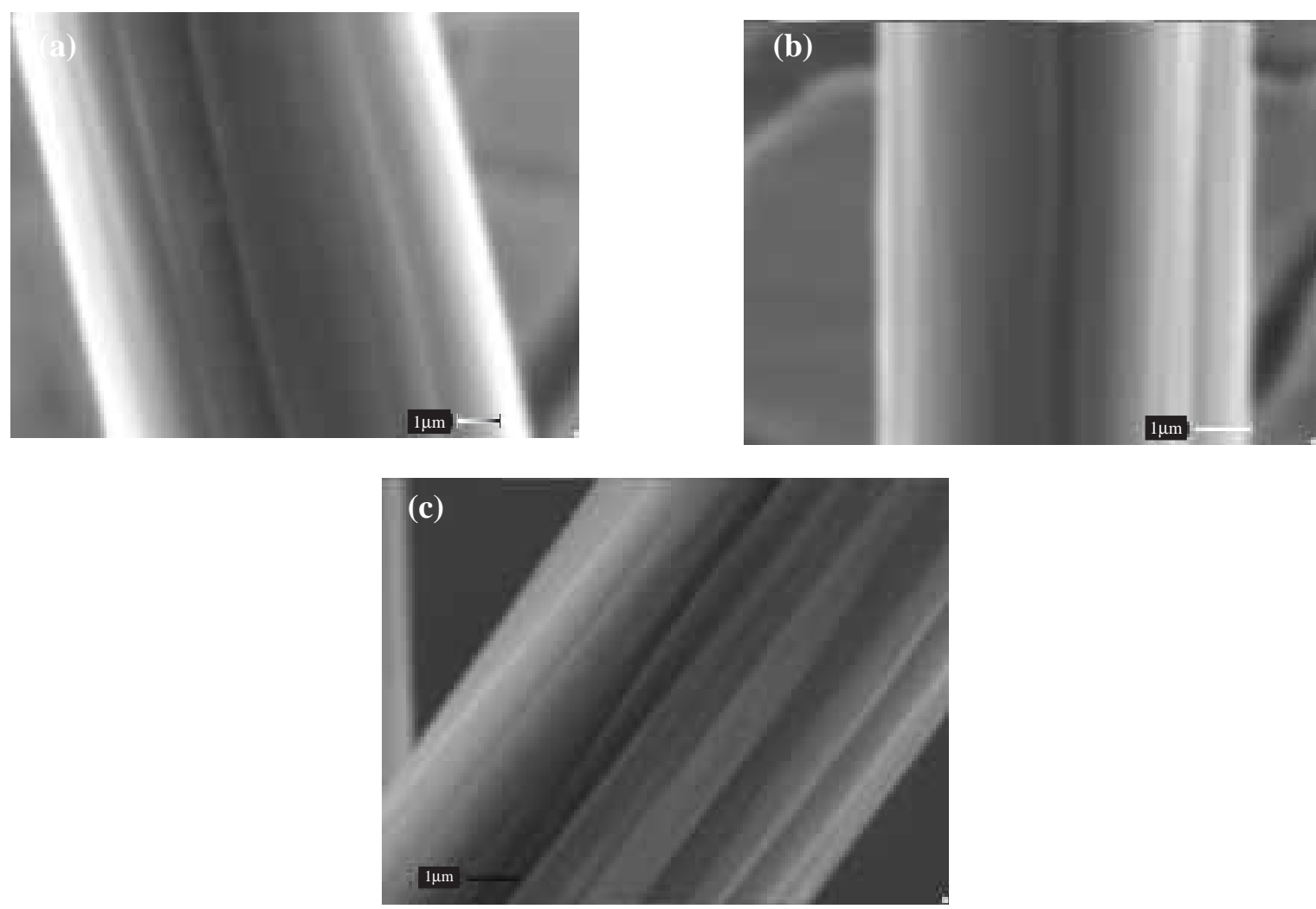

Figura 7. (a) Fibra de carbono tratada com $\mathrm{HNO}_{3}$ por 5 min.; (b) Fibra de carbono tratada com $\mathrm{HNO}_{3}$ por 10 min.; (c) Fibra de carbono tratada com $\mathrm{HNO}_{3}$ por $20 \mathrm{~min}$. 
rugoso, com a profundidade dos sulcos longitudinais mais acentuada. As observações feitas são concordantes com os valores de módulo de Weibull calculados.

A análise das Figuras 7 (a), (b) e (c), representativas das fibras tratadas com o ácido nítrico por 5, 10 e 20 minutos, também revelam modificação da textura inicial, com a presença de vales mais profundos em relação às fibras sem tratamento. A textura observada é semelhante às analisadas para as amostras tratadas com o ácido clorídrico, podendo-se verificar que a amostra tratada por 20 min é a que apresenta o acabamento superficial mais rugoso. As observações feitas nas superfícies das fibras de carbono tratadas concordam com os menores valores de $m$ obtidos na estatística de Weibull, ou seja, o tratamento ácido favoreceu a introdução de um maior número de defeitos, aumentando, consequentemente, a rugosidade superficial do reforço.

\section{Conclusões}

Foi observado que as reações de oxidação, utilizando-se os ácidos clorídrico e nítrico no tratamento superficial das fibras de carbono, ocorrem preferencialmente na região periférica do cabo de filamentos, induzindo a um tratamento diferenciado entre as regiões mais externas e internas do cabo de fibras. Em tempos superiores a $20 \mathrm{~min}$ esse efeito é muito acentuado, danificando os filamentos mais externos ao ponto de impedir o seu manuseio.

$\mathrm{O}$ tratamento dos resultados de resistência à tração pelo uso do método estatístico de Weibull mostra que os tratamentos superficiais utilizados favoreceram à introdução de defeitos na superfície das fibras de carbono, sendo que o número de defeitos aumentou com o acréscimo do tempo do tratamento ácido. Foi observado, também, que o decréscimo nos valores de $m$ para as fibras tratadas por ácido nítrico é maior que o das fibras expostas ao ácido clorídrico, indicando que o ácido nítrico é mais eficaz na alteração da superfície da fibra de carbono.

As observações feitas por microscopia eletrônica de varredura confirmam a presença de sulcos superficiais mais profundos nas fibras de carbono submetidas aos tratamentos ácidos.

Comparando-se os valores médios de resistência à tração e do módulo de Weibull $(m)$ tem-se que, o ácido nítrico introduz um maior número de defeitos superficiais, ou seja, aumenta de maneira mais eficaz a rugosidade da fibra, em um menor tempo de tratamento ácido. No entanto, a resistência à tração do reforço de- cresce de maneira mais significativa que para as amostras tratadas com o ácido clorídrico. Baseando-se somente nos resultados de resistência à tração e nas análises microscópicas tem-se que dentre os meios estudados, o ácido clorídrico mostrou-se o mais adequado, nos tempos de tratamento de 5 e 10 minutos. Análises complementares da funcionalidade da superfície da fibra, correlacionadas com ensaios de resistência ao cisalhamento interlaminar do compósito polimérico processado permitem uma avaliação mais conclusiva do tratamento superficial mais adequado do reforço.

\section{Agradecimentos}

Os autores agradecem à FAPESP (processo 98/ 16353-8) e ao CNPq (processo 300599/96) pelo suporte financeiro.

\section{Referências Bibliográficas}

1. Dilsiz, N. \& Wightman, J. P. - Carbon, 37, p.1105-1114 (1999).

2. Fujimaki, H.; et al. "Process for the surface treatment of carbon fibers”. United States Patent. 4.009.305, (1977).

3. Carvalho, W.S. "Otimização da interface/interfase de fibra de carbono/termoplástico”, Tese de Mestrado - Universidade Federal de São Carlos, Brasil (1988).

4. Cahn, R.W.; et al. - “Materials science and technology”, Vol.13, VCH, Cambridge (1993).

5. Lewis, C. - Mat. Eng., 106, p.37-40, (1989).

6. Pittman, C. U. Jr, et al. - Carbon, 35, p.317-331 (1997).

7. ASTM "Standard test method for tensile strength and young's modulus for high-modulus single-filament materials”. Philadelphia, PA: ASTM, 1982 (ASTM D 3379-75).

8. Ciliato, G.D. "Levantamento Estatístico Utilizando a Teoria de Weibull de Propriedades Mecânicas de Fibras de Carbono". Trabalho de graduação. ITA, Brasil (1996).

9. Burakowski, L. \& Rezende, M. C. “Tratamento superficial de fibras de carbono por método químico”, Anais do $14^{\circ}$ Congresso CBECIMAT, São Pedro SP (2000).

10. Jenkins, G.M. \& Kawamura, K. - “Polymeric Carbons - Carbon Fibre, Glass and Char” (1ª ed), Cambridge University Press, Cambridge (1976).

Recebido: 08/05/01

Aprovado: 13/06/01

Polímeros: Ciência e Tecnologia, vol. 11, noำ 2, p. 51-57, 2001 